\title{
THE VERBAL SUMMATOR AND A METHOD FOR THE STUDY OF LATENT SPEECH ${ }^{1}$
}

\author{
Harvard University
}

B. F. SKINNER ${ }^{2}$

\section{Uses}

The verbal summator is a device for repeating arbitrary samples of speech obtained by permuting and combining certain elemental speech-sounds. One of its uses is comparable with that of ink-blot and free-association tests. The speech-sample does not fully represent any conventional pattern in the behavior of the subject, but it functions as a sort of verbal ink-blot. When it has been repeated a sufficient number of times (the number corresponding to the time of exposure of the blot), the subject makes a conventional verbal response resembling it. For example, a few repetitions of the skeletal sample $a h-u h-u h-00-u h$ may evoke the response stars overlooking. This is by no means the only response matched by the sample, and since it is not evoked by any stimulus acting at the moment, its emergence may be said to be due to its own relative strength. By presenting a wide variety of skeletal samples, an investigator is able to obtain a list of the especially strong responses of his subject. This is essentially what is done in ink-blot and free-association tests.

Aside from its use as a test, the summator is valuable in the study of other aspects of verbal behavior. ${ }^{3}$ When we say that a man uses a certain number of expressions-when we refer to his "vocabulary" -we say nothing about the relative importance of each expression in his behavior. A "vocabulary" does not exist in a uniform state

\footnotetext{
${ }^{1}$ Received in the Editorial Office on April 20, 1936, and published immediately at Worcester, Massachusetts.

${ }^{2}$ Society of Fellows, Harvard University.

"It seems advisable to give the greater part of this account in the loosely defined but familiar terms ordinarily used in discussing language. A much more rigorous formulation is available in reflex terminology, but it would be practically inaccessible in that form to many who may find the material useful. I should like to say, however, that the apparatus and procedure were designed to test the principle of the summator after it had been arrived at theoretically in setting up a system to deal with language purely as behavior, and that a more rigorous presentation of the data will be given in an exposition of that system now in preparation.
} 
of strength. A verbal response $e^{4}$ may be so weak as to be evoked by its appropriate stimulus only after a considerable period of time, as when we have difficulty in recalling a name. On the other hand it may be so strong as to be evoked upon practically any occasion, as when we mention the name of a favorite person at every opportunity. A science of verbal behavior must deal with the conditions of latent speech, whether or not they are significant in a test of the personal organization of the individual.

A static description of the strengths of the items in a vocabulary will not be enough, for changes are constantly taking place. The strength of a verbal response may be a function of a drive-as, for example, when the strength of a child's response Candy falls rapidly during the ingestion of candy. It may also be a function of emotion, as when we are too frightened to talk or when we talk excitedly. Groups of responses vary together during these changes in drive and emotion, and there are a number of other kinds of interconnections between responses based upon similarity of form or connotation. These phenomena will not be considered here, but they may be kept in mind in the following description of verbal summation.

\section{Underlying Principles}

The summator is based upon two familiar principles of non-verbal behavior, which may be extended without trouble to the verbal field. (a) Either as an inherent mechanism or as the result of a very common form of early conditioning, we possess imitative reflexes. I mean by this that certain kinds of stimuli (and the principle is not applicable to all) frequently evoke responses having similar forms. Most children pass through a stage at which a large part of their vocal behavior is of this nature. The child repeats a group of speechsounds exactly as it repeats the sound of an automobile or of a cat'without knowing what it is saying.' In teaching a child to talk we supply a special reinforcement for purely imitative responses, but it should not be overlooked that in adult speech there is also a considerable differential reinforcement in favor of mere imitation. Thus if I am asked, 'What is the relation between $X$ and YQ,' I may begin with the response $T$ he relation between $X$ and $Y \ldots$, which

"Not to be identified with "word." 
may be largely, if not wholly, imitative. I may not be able to go on, but this much at least has been reinforced through its value in 'stalling.' The first principle underlying the verbal summator, then, is that the presentation of a vocal stimulus tends to evoke a response resembling it. (b) The second principle is that of summation. Two responses having the same form summate; and, if each is subliminal in strength, summation may result in the evocation of a response. In the verbal summator we utilize an extension of this principlesimilar but not identical responses also summate, presumably in proportion to their resemblances. If the reader feels that this has not been substantiated experimentally, he may take it as an assumption to be tested by the experiments which follow. Combining these two principles, we may summarize the action of the verbal summator by saying that it evokes latent verbal responses through summation with imitative responses to skeletal samples of speech.

\section{Construction of Samples}

For most purposes we want samples that will summate with many different responses and will at the same time resemble the responses closely enough to have a considerable summative efficiency. These requirements are opposed to each other. In order to summate most efficiently the sample should have the complete form of the latent response, but in that form it would summate very inefficiently with any other. The most efficient way to obtain the response Stars overlooking, is of course, to use the sample Stars overlooking, when only one presentation will suffice. But the result tells us nothing about relative strength because no other responses receive any comparable summative strengthening. On the other hand a single undifferentiated sound would match all responses equally well, but it would have little if any summative action. In the design of skeletal samples we have to find an optimal point between the extremes of complete differentiation and complete lack of it. A set of samples, constructed in accordance with the considerations which follow, have proved to be near this point.

A necessary first consideration is that of temporal and intensive properties, which cannot well be dispensed with. Verbal responses (in English at least) have definite lengths and are syllabic; and the 
samples must resemble them in this respect. The summative range of a sample is restricted by its length, because it will summate only with responses of approximately the same length, but by mixing together samples of three, four, and five syllables it is possible to obtain responses covering a broad range (see below). In English we must also deal with accent, since syllables are not equally stressed. The present set contains two accented syllables in each sample and has therefore nineteen different stress patterns, as follows:
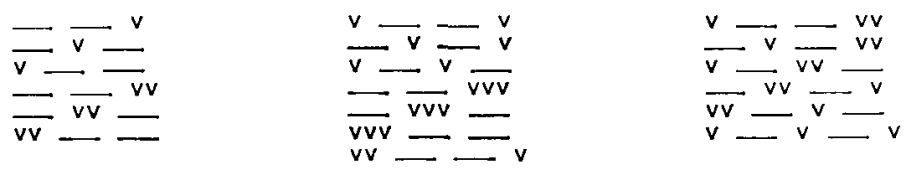

Although this arbitrary selection still further restricts the range of application of the samples, it will be seen in what follows that a wide range is provided for.

Temporal and intensive patterns have some slight summative power of their own without pitch differentiation. I have tried experiments with a buzzer and a motor-driven commutator which made it possible to repeat combinations of from two to six beats timed in any way desired. If repeated a large number of times, a pattern of this sort occasionally evokes a verbal response having similar properties. But the summative efficiency is very low, and the material is usually limited to bits of speech associated with special rhythms-snatches of jingles, marching songs, and so on.

In an efficient set of samples the temporal and intensive pattern must be carried by speech-sounds. All the sounds in a language might be used, but a smaller group of elements is desirable. There are several reasons for omitting the consonants. The juxtaposition of a consonant and a vowel yields a highly differentiated pattern and the range of applicability is narrowly restricted. But vowels cannot well be omitted, for the consonants cannot stand without them. If a choice is to be made, vowels are also to be preferred because they are syllabic, which is an important property of the kind of element required. Another point is that under normal circumstances the consonants are the first to be lost during a reduction in intensity; hence their deliberate omission will sacrifice the realism or verisimilitude of the samples as little as possible. 
The vowel sounds remain as available elements. There are about sixteen of them in American English, but a further reduction is possible. Although in practice the simple vowels are used as if they were discrete entities, they are seen to be merely adjacent ranges on a continuum when expressed in terms of their pitch-composition. ${ }^{5}$ In order to get effective summation we need not follow the traditional division of the continuum, but by selecting a small number of points we may obtain summation with adjacent ranges through spread. The compound vowels, composed of the simple vowels, will be reached through spread also. Or, if we choose a compound vowel, we may expect summation with its components. Thus the simple sound $\ddot{a}$ (far) may be expected to summate with $a$ (fat), $e$ (net), and so on, and the compound sound $i$ (fight) with $\ddot{a}$, $\bar{e}$ (feet), and so on. In designing the set to be described here the six vowels $\bar{e}, \bar{a}, \bar{i}, \ddot{a}, \bar{o}$ (note) and $\ddot{o}$ (move) were chosen as elements. It was found that combinations of these were too rich in differentiated properties and in many cases resembled few or no conventional responses. A seventh neutral vowel $u$ (up) was therefore added as a sort of leaven. The final set was generated by substituting the sound $u$ for all the unaccented syllables in the nineteen different fect and by inserting all possible combinations of the other six vowels as accented syllables. Six hundred and eighty-four samples were obtained in this way, of which the following are examples (where the neutral sound $\mathrm{u}$ is represented with $\left.{ }^{*}\right):{ }^{*} \bar{o}^{*} \ddot{a}^{*},{ }^{*}{ }^{*} \bar{i} \bar{e} *, \ddot{a}$ ${ }^{*} \bar{o} *,{ }^{*} \bar{a} \ddot{o} *{ }^{*} \bar{o} \bar{e},{ }^{*} * \ddot{a} \bar{i}$.

The intonation with which the samples are presented is important. Any change in absolute pitch, either rising or falling, tends to restrict the sample to responses of a definite grammatical structure (question, command, and so on). The samples were accordingly read in as near a monotone as possible. The dominant pitch of the final vowel is nevertheless likely to give some intonational character.

At least two improvements upon this set are possible. After several hours of experimentation a subject may come to realize that the number of different sounds being given is actually quite small. This is an important objection if the illusion of real speech is to be maintained (see below), and a larger number of elements is there-

${ }^{\circ}$ Cf. Paget (1). 
fore indicated for prolonged work. Another improvement could be made by using the elements in proportion to the frequency with which they (and the vowels for which they function vicariously through spread) occur in normal speech, instead of using all the elements equally often as in the present case.

\section{Experimental Procedure}

Samples designed as described above were recorded in random order on 12 -inch aluminum discs. ${ }^{6}$ Fifty samples could be recorded on a single face. The discs were later hardened with a heavy coat of oxide. Thorn needles were used in the reproduction, and little or no effect of wear was noticeable after several hundred playings. For reproduction a repeating device described in the appendix was attached to a standard electric phonograph. The device repeats a given sample every three seconds.

In the set of experiments described below the subject was seated in a quiet room a few feet from the phonograph. A type-written instruction sheet was given to him at the beginning of the first meeting. A sample was presented and repeated until a response was given. The phonograph was silenced (through the intensity control) and the response and the number of repetitions written down. The next sample was then presented. Fifteen seconds usually sufficed between successive samples. A brief rest was given every twenty or thirty responses.

\section{Instructions to the Subject}

Direct Instruction. It is not true that the repetition of a skeleton sample will evoke an overt verbal response. As a result of early conditioning, speech is ordinarily silent. The subject must be given some such instruction as this: 'Listen to the phonograph until you find yourself saying something; then say it aloud.' A second instruction must be added to avoid obtaining the merely imitative response. This may be done by changing the instruction to read 'something with meaning.'

Indirect Instruction. With a direct instruction it was found that the intensity at which the sample was most effective in evoking a

${ }^{\theta}$ I have to thank Prof. F. C. Packard of the Harvard Voice-recording Laboratory for very generous help in the preparation of these records. 
conventional response was very low-definitely above threshold but below a value at which the sample could be clearly repeated by the subject. $^{7}$ The reason for this is that, when the imitative response is strongly evoked, it effectively prevents the appearance of a strengthened latent response. Any strong response, whether imitative or not, may have this effect-for example, the type of nonsensical response which occasionally appears. Examples from the experiments to be described below are Nought sane and The hole boomed up. When such a response occurs, the subject will eventually report that he is unable to follow the instruction and give a meaningful response because a nonsensical response stands in the way. This is also what happens when the skeletal sample is played loudly enough to evoke a strong imitative response.

The optimal intensity, then, is quite low, and at this level a simpler and for some purposes more efficient instruction is available. The direct instruction requires a fairly highly sophisticated mind, which understands what is meant by self-observation. The indirect instruction, which is especially adapted to children and psychopathics, has this general form: 'This is a record of a man saying something over and over again. What is he saying?' The instruction is based upon the assumption that, if the subject hears anything being said, he is saying it himself, even though he is not aware of its origin.

The indirect instruction has the advantage of being understood by the subject and the additional advantage of directing his attention away from the significance of what he is saying. This is important when the summator is being used as a test. Unless the confidence of the subject has been gained, he may resist giving a report of a tabooed response if the response is known to be of his own making. If, on the other hand, he believes the response to be on the record, he may report it without seeming to accept the responsibility. The

\footnotetext{
${ }^{7}$ The actual intensity is dependent upon the hearing of the subject, the acoustics of the room, and so on, but the optimal value is easily determined without taking audiograms or measurements of energy. The two limiting values are given by the intensity at which no response is given at all (which is too low) and that at which the imitative response is evoked (which is too high). These values are close together and a convenient mid-point is easily found. In place of a low absolute intensity, it is possible to use a higher one against a background of noise-an arrangement that is particularly useful where a quiet room is not available. The same method may be used in this case in determining an optimal intensity.
} 
indirect instructions are also valuable in giving the subject a certain assurance, which may be lacking if he is relying wholly upon himself.

There are certain difficulties in maintaining the illusion that the samples are genuine speech. The subject's curiosity about the purpose of the experiment must be satisfied in some way. The true explanation which is available with a direct instruction cannot be used. Instead, the subject may be told, for example, that the experiment is a study of the factors responsible for clarity of speech. At no time must the subject hear the sample played loudly, and other precautions must be taken. ${ }^{8}$ It is sometimes also desirable to ask the subject to spell homophones or unusual terms, but this is hard to reconcile with the pretense that the sample is actual speech and hence well known to the experimenter. As a possible improvement in this respect the subject might be asked to write down his responses, some provision being made for concealing each response so that it would not affect subsequent behavior.

Even though the illusion of speech is maintained, the subject is likely to suspect that he is occasionally making 'mistakes.' A response may be very weak and reported with the kind of indecision that marks a vaguely recalled name. Many responses obtained from summation are also but distantly related to the sample because of the effect of 'spread,' and by comparing his response with another repetition of the sample before reporting it the subject may realize that he is wrong. He may be prepared for this to some extent, if it is explained that some samples have been deliberately distorted. Again, the subject may get responses referring to himself or to private affairs. This can be partially accounted for by telling the subject that the record has been prepared especially for him. Finally, two responses may emerge at about the same time and with equal strength, ${ }^{9}$ and the subject will naturally not believe that both are right. In view of these facts it is advisable to state in advance that mistakes are bound to occur, that they are as useful for the purposes of the experiment as correct responses, and that no concern should be felt about them.

\footnotetext{
${ }^{8}$ When the optimal intensity is being explored, the value at which the imitative response emerges is still low enough to avoid exposing the nature of the material, provided too many examples are not given.

${ }^{8}$ Examples of pairs of responses reported as coming out at the same time: silver plaything-almost anything, forlorn of hope-four on the boat.
} 
The instruction used in the experiments to be described runs as follows:

Explanation of the Experiment. This is a study in clarity of speech. I am going to play a number of short samples of speech on a phonograph and ask you to identify them. You will not be able to hear them very clearly, but they will be repeated many times. Do not invent something to approximate the sample. Listen with care, but simply wait until the phrase pops into your head. If you do not get it at first, do not worry. It will come in time. Do not be surprised if what you get does not match the sample quite exactly, as some samples have been deliberately distorted. Thus, "Away you go" might sound more like "Awai you gow" and so on. Do not be surprised if the samples are fragmentary or absurd. As soon as anything with meaning flashes through your mind, report it at once. Do not wait to check it with the sample. What you get wrong or incompletely is as valuable for the experiment as what you get right. Freely report anything that comes to you as soon as it comes. The success of the experiment will largely depend upon your ability to watch your own mind at work and to detect the appearance of a phrase even though it be feeble or brief.

With this instruction it is possible to put a subject into a receptive and cooperative mood and to obtain a relatively free report of his responses. 'The qualifications listed above do not assume any great importance. The subject is usually convinced that his response is correct. At the end of the experiment one subject reported that he had been certain except when two responses occurred together. Another reported that she had been certain as soon as a response clearly appeared. Another said she usually felt that other responses would also be possible, but her description of the experiment was as follows: 'Funny, they sound like nothing at all until suddenly they sound like something. I listen. It starts saying something. The more I listen, the more it says that one thing.' A fourth subject reported that she had been quite sure until the third and last period of the experiment when she began to doubt her accuracy. When questioned during an experiment, the subjects were usually ready to give quite positive answers regarding details. For example, a subject who gave $A$ large part in response to ${ }^{*} \ddot{a}^{*} i^{*}$ replied 
in answer to a question that the final consonant was $t$ and not $k$. These are fair indications of the effect of the indirect instruction.

\section{Experimental Data: 'External' Properties}

The samples, procedure, and instructions just described have been tested on about twenty persons. In order to make a quantitative estimate of the result I have isolated a block of 1000 responses, consisting of all responses without exception from seven subjects and enough from an eighth to make 1000 . The data given below are for this block unless otherwise stated. The subjects and the number of responses contributed by each are as folows: $A^{\circ}, 135 ; B^{\circ}, 95$; $C^{\uparrow}, 155 ; D^{\circ}, 143 ; E^{\sigma}, 84 ; F^{\circ}, 183 ; G^{\circ}, 142 ;$ and $H^{\uparrow}, 63 .{ }^{10}$

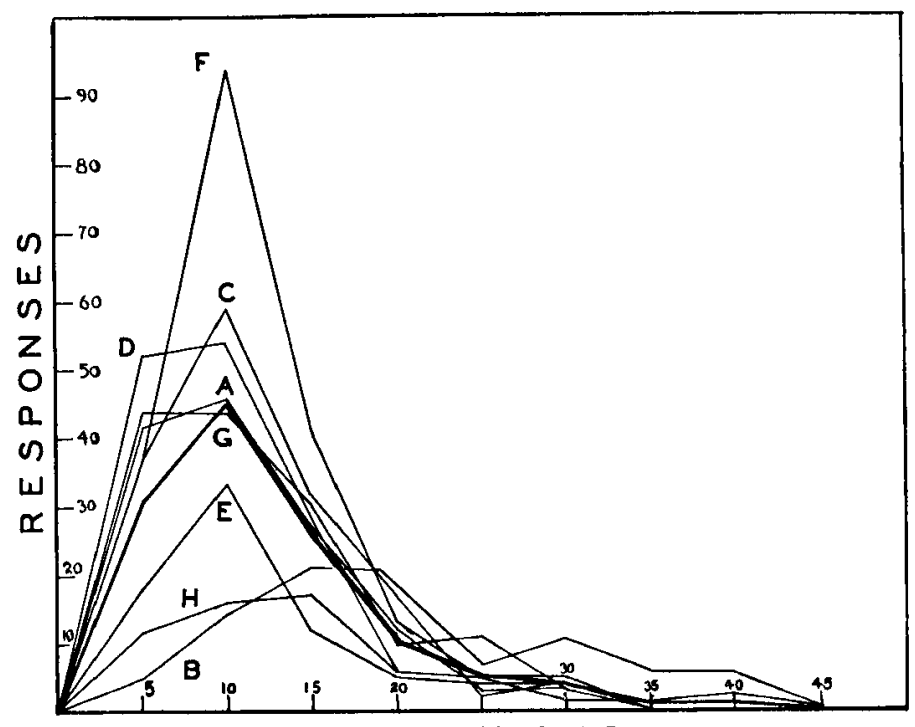

REPETITIONS

FIGURE 1

The Summative Efficiency of the Samples

The number of responses requiring $n$ repetitions (taken in class-intervals of five repetitions) is plotted against $n$. The heavy line is the average for eight subjects, for whom the individual data a re given by the lighter lines.

\footnotetext{
${ }^{10}$ The subjects are either seniors or graduate students in the field of English. I have to thank Prof. H. A. Murray of the Harvard Psychological Clinic for putting them at my disposal and for laboratory space. The psychopathic subjects mentioned below were studied at the Worcester State Hospital with the collaboration of Dr. Saul Rosenzweig.
} 
Number of Repetitions Required. A record was kept of the number of repetitions occurring before each response. The data for the block of 1000 are given in Figure 1, where the total numbers of responses falling within class intervals of five repetitions are plotted against the intervals. ${ }^{11}$ The average (heavy line) is a slightly assymetrical distribution curve with its mode at 10 repetitions. The average for the block is 11.17. In spite of the smallness of the samples the individual data also give fairly normal curves, and with two exceptions the averages fall near 10 . The averages are: $A$, $9.79 ; B, 20.13 ; C, 10.29 ; D, 9.08 ; E, 11.68 ; F, 9.83 ; G, 9.82$; $H, 13.53$. The individual differences are probably significant for $H$ and $B$, but they may be due to several factors. For example, the values may be a function of the tendency to make imitative responses or of the general level of strength of the latent verbal behavior of the subject.

It will be seen that so far as efficiency of summation is concerned, the samples are successful. With an average of 11.17 repetitions a response may be obtained in about half a minute.

Duplication. The other test of a successful sample-that it fail to match any particular response-is also passed by the present set. With very few exceptions (scarcely more than are to be expected from the common cultural background of the group) the samples evoke no common responses. Thus in a group of twelve samples presented to all eight subjects, four elicited no responses having parts in common in analogous positions. (The you in You do drive and Who are you, for example, is not taken as a duplication because different parts of the sample are responsible for it). One sample beginning with $\ddot{o}$ gave three responses out of the eight with you as the initial word, and two other samples gave pairs of you's in analogous positions; but as will be seen later you has a very high frequency of occurrence. One sample gave pairs of move and $g_{0}$, and another gave no, no more, and no more as the beginnings of three responses, but these are also common words. The only significant duplications from the twelve samples are stars, east, and golden, which occurred twice each.

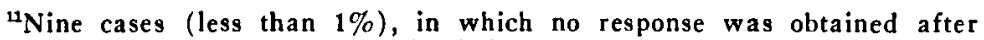
forty repetitions, have been omitted from the block. Hence the zero at forty-five.
} 
The responses of a single person to the same samples upon different days show a somewhat greater overlap, which is to be expected from the fact that the same latent organization is being explored. The subject does not recognize the samples upon the second occasion, and it is doubtful whether any memory effect enters in if the interval between the experiments is reasonably long. An estimate of the duplication may be obtained from the following result for a group of thirty-four samples presented twenty days apart. Twenty-four samples elicited no common response; two samples gave pairs beginning with are; and one sample gave a pair beginning with are these our. Other pairs containing duplications are as follows: pile in your filing-how's your father; were these on the fire-put these on the fire; silver plaything-bring the same thing; do for five cents -at least for five minutes; asleep in the deep-asleep in the deep; did he pay your bill-did you pay Duncan; did you pay her enough-you pay her yourself.

Number of Syllables in Responses. One other desirable property of a set of samples is that it should not closely restrict the length of available responses. The numbers of syllables in the present block are given in the distribution curve in Figure 2. The average curve is nearly symmetrical, as are the individual curves when the smallness of sample is considered. The average curve may be regarded as a description of the probability that a given response will be evoked by this set of samples. A response of four syllables has a maximal chance; one of one or nine almost no chance at all. The maximum could, of course, have been shifted by using samples of different length. Since we have no distribution curve of the lengths of latent responses, we cannot tell how severe a limitation the curve represents. A fairly broad range is provided, however. (It may be noted that much depends upon the definition of a response. Many of the 'responses' obtained are clearly fragmentary.)

From the same data it may be demonstrated that the average response is shorter than the average sample- 4.00 syllables for the former to 4.37 for the latter. Two subjects, however, gave longer average responses-namely, $F(5.01)$ and $C(4.59)$. The other individual averages are $H, 3.87 ; D, 4.15 ; E, 4.28 ; B, 3.82 ; G, 3.53$ and $A, 3.88$. The long responses tend to have few accented syllables, and the subject may even add that the phrase was 'run together.' 


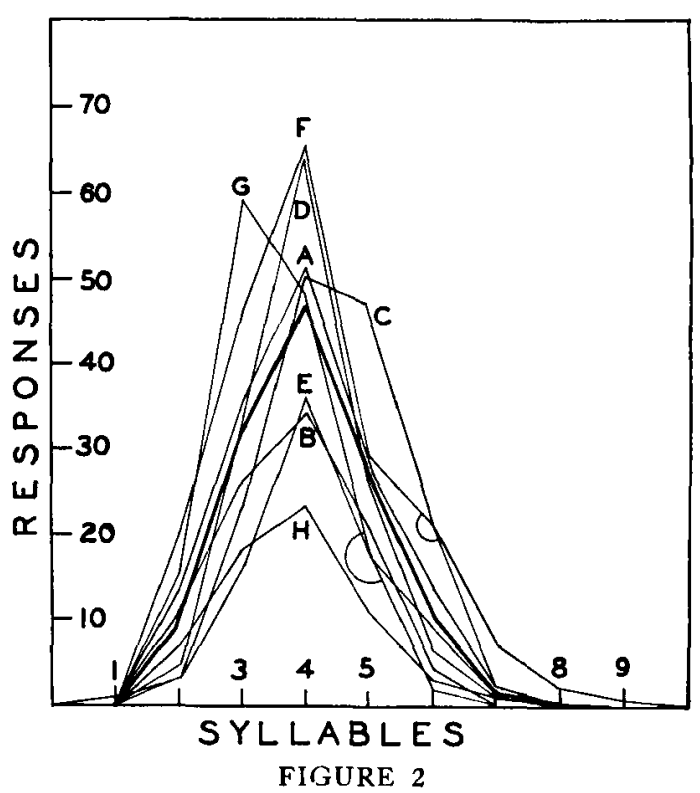

The Summative Range of the Samples with Respect to Length

The number of responses of $n$ syllables is plotted against $n$. The heavy line is the average for eight subjects. The lighter lines are for the individual data.

An example of a long response is Tell him you are going to move now, for the sample $\ddot{a}^{* *} \ddot{o}^{*}$.

Phonetic Distortion. It was expected that the extent to which the sample was distorted by the response would be a significant datum, but the distortion proved to be very great and in many cases a point-to-point comparison of the vowels in sample and response impossible. The accuracy of the phonetic material suffers to some extent under the conditions of the experiment. In spite of the very good reproduction provided by the recording and playing apparatus there is considerable modification of the pitch-intensity pattern at the low intensity used in the experiment. The fidelity may be gauged from the following data on my own responses in noting the samples in the protocols. I heard the samples only slightly more clearly than the subject, and the list was too long and too repetitious to be memorized. When taking the notes I had no intention of using them in this 
way; they were written down hastily for later correction. The significant confusions (all those above 2 per cent) were as follows. The sound $\bar{i}$ was noted down as $\ddot{a} 14.7$ per cent of the time and $\ddot{a}$ as $i \mathbf{i} 4$ per cent. This confusion was probably due to the inclusion of the sound $\ddot{a}$ in $i$. That it holds principally in the direction of $\bar{i}$ to $\ddot{a}$ may indicate a loss of the higher pitched $\bar{e}$-component in $\bar{i}$. The sound $\ddot{o}$ was written as $\bar{e} 7.6$ per cent of the time and $\bar{e}$ as $\ddot{o}$ 2.8 per cent. Phoneticists who are accustomed to thinking in terms of the production of vowel sounds place $\ddot{o}$ and $\bar{e}$ at opposite poles. They are actually quite near each other in pitch composition (1). The sound $\bar{a}$ was written as $\bar{o} 7.0$ per cent and $\bar{o}$ as $\bar{a} 4.4$ per cent of the time.

In view of this phonetic inaccuracy and of the great freedom of distortion exercised by the subjects I have not regarded it as profitable to tabulate the sound changes in the experiment. Their general nature may be discovered in the sample protocol given later.

VII. Experimental Data: Word-Distribution Compared With Normal Speech

Word-Frequency. An interesting uniformity in normal speech has been demonstrated by Zipf (2), who has shown that for samples as diverse as Plautinian Latin, Peiping Chinese, and American newspaper English, a relation obtains between the number of words occurring at a given frequency and that frequency. I shall not examine the validity of the term "word" in this statement but shall accept (in the absence of a rational interpretation) a method of analysis that yields the relation. All discrete forms are counted as separate entities. 'The word child may be considered as one word, children as another, give a third, gives a fourth, given a fifth (2).' With this definition of 'word' a straight line is obtained on logarithmic coordinates when the number of occurrences is plotted against the number of words.

Our block of 1000 responses contains 3046 words, of which 476 occur once, 133 twice, 65 three times, and so on. The relation between number of occurrences and the number of words is given in Figure 3. A straight line has been drawn to indicate the relation expected for normal speech. It is obvious that the points are slightly low in the middle range and too high at the extreme left, but al- 


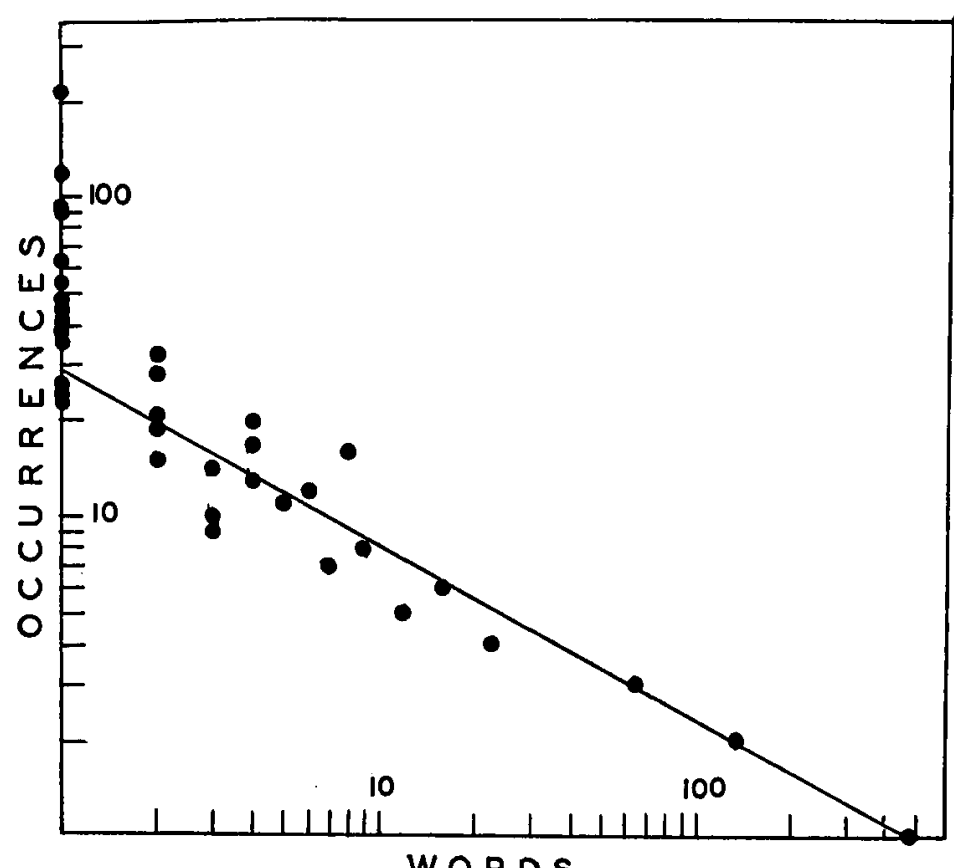

FIGURE 3

Approximation to Zipf's Law in a Block of 1000 Summated Responses The straight line shows the relation approximated in normal speech.

though the scatter is somewhat greater because of the smallness of the sample, the fit is very nearly as good as that reported by $Z$ ipf. In the group for newspaper English a uniformly curved line would give a better fit, and in general the law does not hold for the few words occurring most frequently. The present data differ in being best fitted with a curve concave upward, and in particular in the fact that the few words occurring most frequently occur too often rather than too seldom as in the case of normal speech.

I think it may be fairly said so far as this property is concerned, the material obtained with the summator closely resembles normal speech. If this be granted, the application of Zipf's law to verbal behavior is considerably restricted. It presumably does not refer to any property of behavior (such as that of the "selection" of 
an appropriate word) which is not present also in the case of summation. On the contrary the law seems to be a description of precisely what I am here investigating-the condition of strength in which latent speech exists. The elicitation of normal speech is generally related to past or present external stimuli. We usually talk about something, and it is frequently assumed that external stimuli control the frequencies with which words occur. But where a statistical study is extended to a large number of cases, the stimuli become incidental and practically irrelevant. As a matter of practice, they are ignored in the greater part of linguistics, and the present point is something of a justification for this. The strengthcontour of the reserve of latent speech is finally reproduced in a statistical study, because by taking a very large number of instances the incidental effects of particular stimuli are averaged out. To put it roughly - what there is for us to talk about is eventually not so important as what we have to say.

The verbal summator does directly what a study of word-frequencies in normal speech does indirectly. The summator elicits responses in the absence of appropriate stimuli; the world-count eliminates the effects of stimuli by averaging them out with large numbers of cases. With either method we arrive at a description of the relative strengths of verbal responses.

Word-percentages, Another uniformity in the distribution of words in normal speech is the relation between the percentage of the bulk made up by a word and the rank order of the word. The relation is especially valuable here because it holds for the words which are not correctly described by Zipf's law. The data given by Dewey contain the percentages of the whole sample contributed by each word. When plotted on logarithmic paper the values closely approximate a straight line, as shown by the lighter line in Figure 4 , which is for the data quoted by Fletcher (4). In the same figure the data for our block of 3046 words are given in the heavier line. It will be seen that the two sets are very similar. The percentages of the most frequently occurring words are almost identical, although in terms of absolute number of occurrences the samples seemed to differ most noticeably at this point. The curves draw apart slightly at the lower frequencies. It may be noted that the curve for summated speech gives the better approximation to a straight line. The 


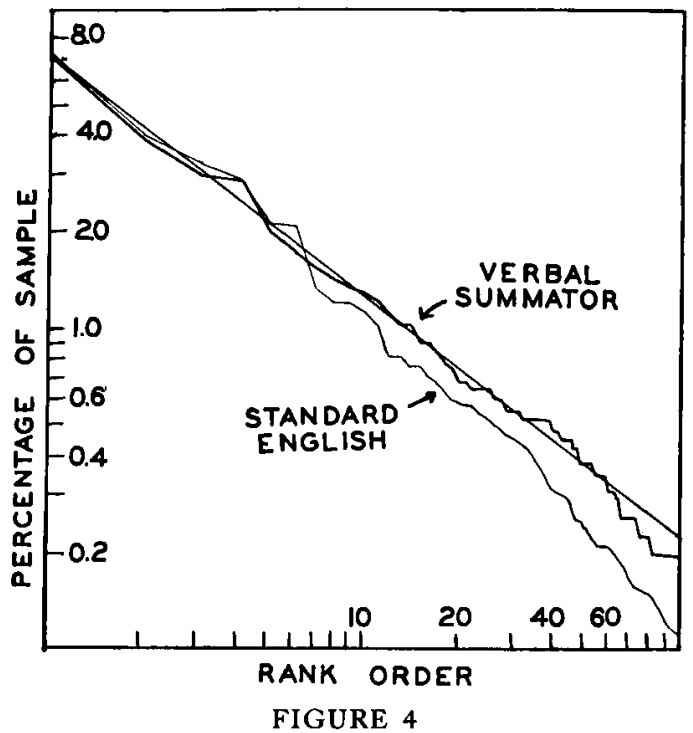

The Close Resembiance between Standard and Summated Speech with Respect to The Distribution OF Word-Percentages

only significant deviation is for points representing words occurring very infrequently.

That two sets of data as widely separated in their origin as Dewey's standard American English and the material collected with the verbal summator should yield curves so nearly identical is, I think, remarkable. It is difficult to sce why the words occurring with the four highest frequencies in the two sets should have percentages as much alike as 7.12 and $7.31,3.92$ and $3.99,3.02$ and 3.28 , and 2.95 and 2.92 respectively. It is further support for the view that with the summator and a statistical study of actual speech we are exploring the same mechanism. The summator draws upon the reserve of verbal behavior which lies behind and controls the ultimate character of normal speech.

Word-rank. The agreement between summated and normal speech shown in Figure 4 appears all the more remarkable when it is noted that the actual words occupying the positions of most frequent, next most frequent, and so on, are not the same in the two cases. A list of the summated words occurring fifteen times or 
oftener in the present block of material is given in Table 1, which also gives the number of occurrences and the percentage of the bulk for each term. For comparison with standard English the position of each word in Dewey's list and the percentage of the bulk contributed by it to that sampling are also given. The two lists agree to the extent that thirty-five out of the forty most frequent words in the present list are found among the 100 most frequent words in standard American English. But the orders differ greatly. Certain words (e.g., you, are, do go), have moved upward and others have necessarily been displaced.

In seeking an explanation of this difference one naturally turns to the samples used in summation. Since the set was generated from elements occurring equally often rather than in proportion to their frequency in normal speech, it is possible that certain common forms have been favored and others militated against because of their sounds. Thus you may have been forced upward into first place because of an abundance of $\ddot{o}$ 's, while and may have dropped behind because the $a$-sound is dependent upon spread from $\ddot{a}$. But an examination of the actual displacements lends small support to this view. In the forty words in Table 1 thirty have bettered or maintained their standard position and ten have moved downward. In the former group 33 per cent of the vowels do not occur in the elements of the samples, and consequently movement upward must be possible without special summating support. Likewise the vowels of fifty per cent of the words moving downward do occur in the samples, and hence demotion is not necessarily due to lack of support. The samples may be responsible for the difference to the slight extent indicated by the fact that sixty-six per cent of the responses moving upward, but only fifty per cent of those moving downward, contain elemental vowels. More important factors in accounting for the difference appear in the following paragraphs.

\section{ViII. Experimental Data: Grammatical Forms}

Effect of Length of Sample. The responses elicited with the present samples are from two to six syllables long with a maximum at about four. The distribution curve in Figure 2 represents the limitation of the power of the samples to evoke responses of different lengths. Now, the type of response resulting from the summation is 
TABLE 1

\begin{tabular}{|c|c|c|c|c|c|}
\hline Order & Word & Occurrences & $\begin{array}{l}\text { Per cent } \\
\text { total }\end{array}$ & $\begin{array}{c}\text { Standard } \\
\text { order }\end{array}$ & $\begin{array}{c}\text { Standard } \\
\text { per cent }\end{array}$ \\
\hline 1 & you & 217 & 7.12 & 15 & 0.77 \\
\hline 2 & the & 120 & 3.93 & 1 & 7.31 \\
\hline 3 & a & 92 & 3.02 & 5 & 2.12 \\
\hline 4 & are & 90 & 2.95 & 24 & 0.54 \\
\hline 5 & do & 63 & 2.06 & 63 & 0.20 \\
\hline 6 & go & $5 t$ & 1.77 & $100+$ & $<0.11$ \\
\hline 7 & have & 48 & 1.57 & 19 & 0.61 \\
\hline 8 & it & 44 & 1.44 & 8 & 1.21 \\
\hline 9 & of & 42 & 1.38 & 2 & 3.99 \\
\hline 10 & he & 40 & 1.31 & 17 & 0.68 \\
\hline 11 & on & 38 & 1.25 & 18 & 0.64 \\
\hline 12 & I & 35 & 1.14 & 10 & 1.15 \\
\hline 13 & how & 32 & 1.05 & 91 & 0.12 \\
\hline 14 & to & 32 & 1.05 & 4 & 2.92 \\
\hline 15 & and & 28 & 0.92 & 3 & 3.28 \\
\hline 16 & up & 28 & 0.92 & 62 & 0.20 \\
\hline 17 & over & 26 & 0.85 & 79 & 0.15 \\
\hline 18 & your & 24 & 0.78 & 56 & 0.21 \\
\hline 19 & me & 23 & 0.76 & 47 & 0.25 \\
\hline 20 & that & 21 & 0.69 & 7 & 1.34 \\
\hline 21 & we & 21 & 0.69 & 25 & 0.52 \\
\hline 22 & these & 20 & 0.66 & 81 & 0.15 \\
\hline 23 & who & 20 & 0.66 & 50 & 0.24 \\
\hline 24 & with & 20 & 0.66 & 16 & 0.72 \\
\hline 25 & now & 20 & 0.66 & 59 & 0.21 \\
\hline 26 & all & 19 & 0.62 & 29 & 0.46 \\
\hline 27 & know & 19 & 0.62 & $100+$ & $<0.11$ \\
\hline 28 & did & 17 & 0.56 & $100+$ & $<0.11$ \\
\hline 29 & in & 17 & 0.56 & 6 & 2.11 \\
\hline 30 & my & 17 & 0.56 & 45 & 0.29 \\
\hline 31 & no & 17 & 0.56 & 40 & 0.32 \\
\hline 32 & boat & 16 & 0.53 & $100+$ & $<0.11$ \\
\hline 33 & don't & 16 & 0.53 & $100+$ & $<0.11$ \\
\hline $3+$ & is & 16 & 0.53 & 9 & 1.21 \\
\hline 35 & not & 16 & 0.53 & 21 & 0.58 \\
\hline 36 & out & 16 & 0.53 & 64 & 0.20 \\
\hline 37 & them & 16 & 0.53 & 53 & 0.22 \\
\hline 38 & us & 16 & 0.53 & 93 & 0.12 \\
\hline 39 & her & 15 & 0.49 & 54 & 0.22 \\
\hline 40 & what & 15 & 0.49 & 48 & 0.25 \\
\hline
\end{tabular}


affected by this limitation. Relatively short responses are favored, and elaborate grammatical constructions are practically lacking. Thirty-three per cent of the block of 1000 responses are nouns, adjectives, adverbs, and so on, standing in absolute position. Consequently there are fewer prepositions and conjunctions than in normal speech, and this accounts for the principal difference in the word-rank that has just been noted. Words which are strongly affected by the limitation are and, but, or, as, that, with, from, by, at, in, and many others. The definite article, which very frequently accompanies nouns in sentences, is more often omitted in absolute position, and the rank order of the also suffers from the limitation of length.

Effect of Extraneous Stimuli. The summator is designed to obtain verbal responses in vacuo, so to speak. Stimuli which dictate the elicitation of one response rather than another are eliminated so far as possible. The ideal condition in which they are altogether lacking cannot be fully achieved, but it is realized to a considerable extent, and the material obtained is as a result affected by a reduction in the number of 'statements about things.' The 'declarative sentence,' which makes up the greater part of normal speech, is reduced to 16 per cent of the total sample. The effect upon the word-rank is the downward displacement of the copula is (and also be) and of the auxiliary forms for other tenses than the present, particularly had, has, and been. The other grammatical forms, especially the question and the command, are less dependent upon extraneous stimuli and consequently appear with greater relative frequencies than in normal speech. This frequency is also due to some extent to the stimuli present, of which the most important may be roughly described as the 'situation.' 'The experimenter and the subject constitute the sacial group within which the verbal behavior is evoked. One direct effect is the upward movement of you, another the predominance of questions and commands. Questions compose 22 per cent and commands 14 per cent of the total block. Both of these forms contain a high percentage of verbs, and they are responsible for the upward movement of such forms as do, did, don't, go, going, know, leave, see, and so on.

Responses not included in these four classes make up 15 per cent of the whole. They include nonsense (2 per cent), exclamations 
(2 per cent), and incomplete responses with unidentifiable form (10 per cent).

\section{IX: Experimental Data: The 'Content' of the RESPONSES}

External Stimuli. We now reach the point of accounting for the emergence of specific forms or, if no account can be given, of interpreting them in the light of a 'test.' The first factor responsible for specific form is the fortuitous external stimulus. In the present experiment the subject was seated in a lighted room, which was quiet but not sound-proof, and the apparatus and the experimenter were visible. Approximately 3.5 per cent of the responses in the block are traceable to specific stimuli from these sources. This does not mean that the subject was 'talking about' the stimuli in the usual sense. The responses were believed to be on the records, but their relation to extraneous stimulation was readily apparent to the experimenter and in one or two cases to the subject a posteriori.

Such stimuli may be conveniently divided into three groups. The first includes the objects and circumstances present and conversation with the experimenter before the experiment or during rest periods. One subject watched the experimenter as he adjusted a small knurled wheel on the apparatus and gave as her response to the first sample What wheels do you touch? A needle sharpener used during the experiment, which was shaped like a top and called the Red-Top Sharpener, was occasionally mentioned, as in He bought a top, A needle for the top, and so on. A distant clock striking the half-hour led within a minute to the response Half-past. The sound of an automobile horn outside the building led to the response $A n$ automobile. Loud talking in the hallway gave Loudmouth. When the experimenter questioned a subject as to whether a response had been Go $u$ p or Grow up, the following response was Grow up and go. A short conversation about Thoreau's $W$ alden was followed by the response Behind the hut, and the subject commented, "Sounds like Walden."

The frequent occurrence of $\mathrm{How}$ do you do or a similar greeting near the beginning of an experiment may be a similar case, but greetings occur elsewhere and may be omitted from this class. An 
unusual example, not in this block, was obtained from a psychopathic subject who gave as his second response Return the words and they'll be fixed up in the office, which was his interpretation of the experiment and of his part in it. A comparable case in which an external stimulus asserted itself occurred with a young girl, aged $7 \mathrm{I} / 2$, who repeated several bits of a conversation going on in the hall-way although she was listening to the phonograph and was quite surprised when the source of what she was saying was pointed out to her. Fourteen examples of this kind occur in the block.

The second kind of stimulus is supplied by the manner of presentation of the speech-samples. There are occasional responses of the form Call them louder, or Make it closer, or Force them harder, which seem quite definitely to be directed toward the low intensity of reproduction. Do you hear me, We ought to hear him, Hard to repeat, A little more difficult, and so on, are of a similar sort. There are eleven examples of this kind in the block.

The third group are proprioceptive stimuli. The procedure of the experiment is likely to produce drowsiness, and there are numerous references to sleep, as, for example, $W e$ wanted to sleep, Look out, you're going to sleep. The subject may also tire of the experiment and look forward to its termination; hence such responses as Whole hour yet, Time will soon pass. Is this the last one, Please let me go home, and so on. Coming to the experiment directly after lunch one subject gave How full I am. Twelve cases of this sort have been identified in the block.

There are also a few responses which seem to comment upon the experiment more generally, but it is difficult to prove their relevance, and since they are in any event rare, they may be ignored.

This result has a peculiar interest of its own. Here is a condition in which a man 'makes a statement' about something in his environment, while fully believing that he is repeating what is being said by a phonograph. He may immediately notice the connection with the stimulus by commenting upon the 'coincidence,' and if the true nature of the sample is explained, he may recognize that he has 'made a statement.' This is very close to the kind of double response that lies behind 'knowing what we are saying.' In the normal case the two responses occur so closely together as to make the identification of their order very difficult. It is traditionally assumed that 
we notice connections and then speak of them, but the reverse order -that we speak and then notice the connection-has much to recommend it, especially since 'notice' may then be translated into verbal terms. This is a very difficult subject, and I wish here only to point to the relevance of the material.

Perseveration. A second factor to be noted in accounting for specific forms may be called perseveration. It is readily discovered in a list of responses obtained with the summator. A word or theme makes its appearance, persists for a time, and disappears. In view of this fact a single member in a list cannot be regarded as unrelated to adjacent members. The responses themselves set up a condition which affects subsequent responses and which works against the free emergence of a response according to its latent strength.

Although perseveration is conspicuous enough in the data, a formulation of what is happening is made difficult by the necessity of reconciling the process with the laws of word-frequency already examined. A distinction must be made between saying that one occurrence of a given word is responsible for a second occurrence (in the sense that the second would not otherwise take place) and saying that it is responsible for its proximity (in the sense that it would otherwise have occurred at some later time). The first view is seen to be improbable when carried to the extreme, because it would make perseveration wholly responsible for the word-frequencies that we have noted. The second view, which I think is to be preferred, takes the final word-score as an indication of a latent reserve that makes itself felt in proportion to the strengths of its parts, provided temporary biases may be eliminated or averaged out. Under this view perseveration acts to pull together responses which would be distributed in another way if their elicitation were left to chance. I shall return to this point shortly.

It is not easy to demonstrate the 'attraction' of one word by another when the form occurs frequently, but I have tried to confirm the casual impression of perseveration by examining all instances of words which occur twice and twice only (where both occurrences fall within a single experimental period). There are 135 cases of this sort. Given a series of definite length, the probability that a pair of responses will occur $n$ responses apart, if the two are in. serted in the series at random, is a linear function of $n$. Thus, in a 
series of ten responses, there is one possible arrangement in which the pair may be separated by nine intervals-between-responses, two arrangements in which it may be separate by eight, three by seven, and so on. The series available for analysis here are not of equal length but are nearly enough to show the non-linearity of the relation. In Figure 5 I have chosen a class-interval of five and have plotted the

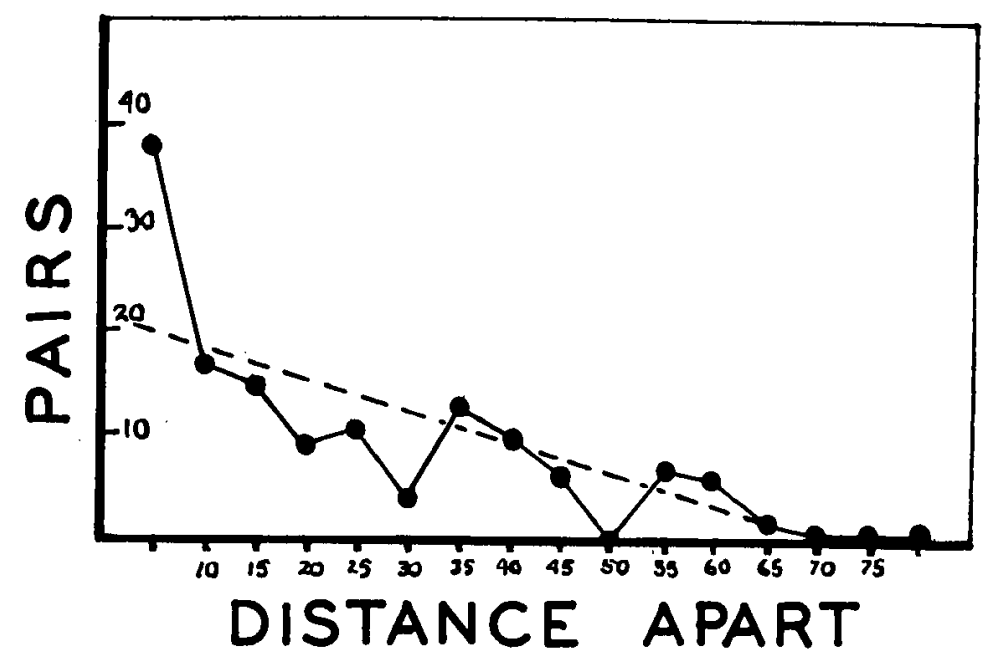

FIGURE 5

Perseverative Attraction between Words Occurring Twice Only in a Single Perion

The broken line shows the approximate relation to be expected from chance. The experimental result differs chiefly at the class-interval of five units of distance, showing an attraction of the second occurrence by the first that is operative at close range only.

number falling within each interval against the class. The dotted line indicates the probable distribution, although it is only approximate because of the slight difference in the lengths of the series. It will be seen that there is a clear tendency for the second member of a pair to occur within five responses following the first. 
Where the unit is taken as the 'word,' either the form or the content may be responsible for the perseveration. Fortunately these factors are separable, for there are examples of the perseveration of form (the mere sound) without perseveration of sense. The examples have the form of puns. One subject gave the series Harry Goldman,-, In a gold mine, where there is a pun on the name Goldman. Another gave Your air of defeat,-, Full of air, where the senses of air are different. Another gave How amazing, How is he, How marvelous, where the meaning of how changes and then changes back. A psychopathic subject not in this group gave a long series in which hire and higher were freely intermingled. This kind of pun is to be distinguished from that which distorts the form. The latter has had a recent vogue as a form of humor although it is an ancient device. In a common form the request, 'Give me a sentence using th word $x$,' is answered by using the form in an unexpected and usually slightly distorted way. At least one example of a distorted pun appears in the block of 1000 responses. The subject had given the series Three or four years ago, Historical article. Thirtyseven responses later she gave Slightly historical, which may be regarded as an unconsciously humorous distortion of the trite phrase slightly hysterical.

We have no reason to confine the action of perseveration to the word as a unit. Alliteration and rhymes are normal examples of perseveration below the level of the word, and they are common in the present material. An example of a triple perseveration of initial sounds is the series Hire a bootblack, Have a bluebook. Examples of terminal rhymes are (a) Blow that fuse up,-, No shoes up, (b) Trial by another, Is he your brother, (c) Over golden seas, There are men at ease. Internal rhymes and assonance also occur (No rule better, No more butter). Perseveration above the level of the word (that is, of phrases and so on) is also demonstrated. Other kinds of formal perseveration are:

(a) Grammatical structure. Questions, commands, and so on, tend to occur in groups. 'The effect also holds for such constructions as in You and me, Now and now and Round and round, Row on row, half and half.

(b) Dialect or tongue. A phrase in French or German is often 
followed closely by another. This is true of dialect and cant, as in the series, You "now" of it, You were "hoit."

There is also perseveration of sense or theme without perseveration of form. Examples of perseveration of theme are: Two four one eight, Call station (telephone), The music passed you, What's this motif? (music) Grand orchestra, You're musical (music) God of Love, Come near the earth (religion) Make a full stop, Slow Motion (speed). The last was followed by Go to movie, which is a further example.

With regard to the relation of perseveration to word-frequency, it may be noted that, although perseveration of theme has an effect similar to perseveration of form in determining that certain responses are to follow, the same word is not involved and an effect upon the word-count is lacking.

A simple way to state the fact of perseveration is in terms of the covariation in strength of groups of related responses. A group mav be related in form or content. Similarity of form is involved in both cases, although in the latter the form is in the stimulus with which the words are correlated - that is, in their referents. Perseveration is a figurative way of saying that when a member of a group is elicited, all members of the group are temporarily strengthened relative to their normal latent strengths. Thus, if I say hire, all my responses which resemble that response are temporarily strengthened -particularly the response hire itself, which is likely to be elicited again sooner than its resting strength would dictate, and higher, which leads me to pun. Also strengthened are all words beginning with $h$ (hence alliteration) and all ending in ire (hence rhyme). As to perseveration of theme, my response hire strengthens all re. sponses associated with its referent, and I am likely to 'go on' to speak of labor, wages, and so on.

It would be uneconomical to appeal to covarying classes of this sort if they were useful only in accounting for perseveration. But they are demanded for many other reasons in a treatment of verbal behavior and are, indeed, one of its most important properties. The phenomena of bilingualism and of synonymity and the definition of such terms as 'complex' and 'idea' require some such scheme. In the perseveration of form the only mechanism appealed to is summation, with which we began. The perseveration of theme be- 
longs in a separate category, which in its broadest sense includes the phenomena of drive, emotion, and so on, which are comparable examples of the covariation of reflexes having little or no similarity of form. These problems can obviously not be taken up here.

In reconciling perseveration (as a force which seems to create additional occurrences of a response) with the notion of a latent reserve (which is supposed ultimately to dictate the number of responses that are to occur), we may simply note that summation and facilitation are temporary states of enhanced strength, and that responses elicited at any time through their intermediation may be compensated for by later subnormal activity. Such compensation is very common in infra-human (and non-verbal) behavior. For a brief discussion of the relation of temporary facilitation to a latent reserve the reader may be referred to (3).

Perseveration of theme without form is to be distinguished from what may be called Chaining, in which one response provides the stimulus for another. Examples are: (a) Where are you going, Home as usual, (b) Who are you, I couldn't imagine, (c) Will you have tea, All right, I'll ring the bell, (d) My eye's on the rope, What did he do, He pulled the rope, (e) I love you, Do you love me? Another effect that should perhaps be given a separate listing may be called Completion. The response given to one sample is incomplete but is completed with the next sample. Examples are: (a) Pay or else, or move out, (b) You are on the road, The wrong road.

Infrequently there is evidence of a chain all of which has not been given overtly or of an internal relation between responses not falling into the above classes. For example, in the protocol reproduced below, the response $Y$ ou are a peanut appears during the first day. On the second day the response $Y_{0} u$ are a peacock is followed by Are you a nut? It is a reasonable inference that the response You are a peacock was first followed by some verbalization about the previous response $Y_{o u}$ are a peanut ending with the overt question Are you a nut? It is difficult to deal with these questions in any satisfactory way because of the meagreness of the data.

As a sort of summary of perseveration I shall give the following consecutive series of responses from the protocol reproduced below and comment upon some of the interrelations which it exhibits. 


\author{
Elle n'est partic \\ Do not say your part \\ Take leave of it \\ Oh, are you? \\ Got your visa? \\ Elle ne sait pas \\ $P$-p-partie \\ Are you going? \\ Who are you? \\ Vis-à-vis.
}

Perseveration of form without sense is shown in the pairs: partiepart, not say ... part-ne sait pas, visa-vis-à-vis. Perseveration of sound and sense is shown in elle n'-elle ne, partie-partie, are youare you-are you, and so on. There is perseveration of theme without form in partie, take leave, are you going, and perhaps got your visa. $P$-p-partie is probably due to the fact that when the first response was given, the subject was asked whether it was partie or pas partie. The response Elle ne sait pas may have recalled the first (very much as You are a peacock recalled You are a peanut), and the silent correction to pas partie became overt in a disguised form as the sound of someone stuttering.

Sample Protocol. The following protocol is the complete record for Subject $A$. Each entry includes the sample (e.g., $i^{* *} a^{*}$ ), the response (e.g. barley), and the number of repetitions required (e.g., 15).

$I^{* *} a^{*}$ barley $15 ; \ddot{a} 0^{* * *}$ have hold on that $3 ; \ddot{o}^{* *} e$ do not do that $7 ; i{ }^{*} i^{*}$ spell the party $13 ;{ }^{*} \bar{e} \ddot{a}^{* *}$ have you pummelled him 4 ; **ēo how do you do 21; *äi good-night 5; *ēe*ä you know a part 9; *aī cracker 16; ${ }^{*} \ddot{o}^{* *} \bar{o}$ have you anything $6 ; \bar{e}^{* *} \bar{a}$ two four one eight 3 ; $\bar{o} \bar{a}^{* *}$ call station $8 ;$ *io* $^{*}$ sour pickles

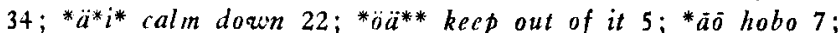
$\partial^{*} a$ do it again 5; ${ }^{*} 0^{*} i^{*}$ you are mine 5; **ä̈* l knew her 5; $i^{*} \ddot{o}^{*}$ Mannheim vis-a-vis $29 ; \bar{e}^{* * *} \bar{a}$ Lita hit . . . 18; ***āo get over main jump $15 ; \ddot{o} i^{*}$ you tried them 3 ; ${ }^{*} e^{* *} \ddot{j}$ he has you 8 ; $\bar{e} a^{* *}$ he never hurts you 12 ; ${ }^{*} \bar{e}$ Heidi 10 ; **ö $\ddot{0}$ a Bilderbuch 15; ${ }^{*} a^{*} \tilde{o}^{*}$ holding one over $10 ; a^{* *} \bar{\rho}^{*}$ why have you 10 ; (rest); ${ }^{*} \bar{a}^{*} \bar{o}$ Tabelletuch 40 (reported only after repetition had been stopped); $\ddot{e}^{* * *}$ if $I$ were you 9; **äö are you old enough 6 ; $\bar{a}^{* * *}$ have you forgot 9 ; $\bar{e}^{*} \bar{\imath}^{*}$ who are you 3 ; ${ }^{*}{ }^{*} \ddot{a}^{*} I$ couldn't imagine $18 ;{ }^{*} \bar{a}^{* *_{i}}$ Which am I $18 ; \bar{e}^{* *} \ddot{a}^{*}$ America $11 ; i i^{* *} \ddot{o}$ could 1 get on with you $6 ;{ }^{*} \bar{e} a^{*}$ 
who are you 12 ; $\bar{o} \bar{o}^{* *}$ will you come back 12 ; "āö** no may . . do that 28; **ä Dumas $13 ; \bar{a}^{*}$ don't go there $20 ;{ }^{*} a^{*} \bar{i}^{*}$ watch my margin 15; $*^{*} \bar{o}^{*} \bar{e}$ after all my duty $5 ; i^{* *} \bar{e}^{*}$ Ay like a bee 10 ; (rest); $\bar{e} \bar{e}^{* * *}$ did you have a fight 3 ; ***öi what'll you do now $12 ; \bar{a}^{* *} i^{*}$ do your part $7 ; \bar{e}^{* * *} \bar{o}$ you got in my boat 13 ; "ait. . . out of it $12 ; \bar{e}^{* *} \bar{a}$ you are to wait 12 ; $\ddot{o} \bar{a}^{* *}$ go down avith it 7 ; **ōo Gauguin 12; äं* hoqu now 10; *öa you said it 8; **ä $\bar{a}^{*} \bar{e}$ from $A$ to $Z 6 ;{ }^{*} \bar{e}^{*} \ddot{a}^{*}$ you tire me 7 ; ${ }^{*} \bar{o}^{*} \bar{a}^{*}$ no one over 4 ; (rest); $a^{* *} \ddot{o}^{*}$ blow that fuse up $6 ;{ }^{* *} \ddot{a}$

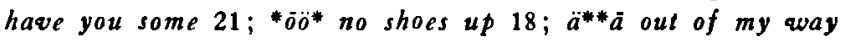
12; $\ddot{\partial}^{*} \bar{o}^{*}$ (no response in 40 repetitions); $\bar{e}^{* * *}$ (no response in 40 repetitions); $\ddot{a} \bar{o}^{*} I$ believe it $5 ;{ }^{*} a \ddot{o} I$ rode $12 ;{ }^{*} \bar{e}^{*} \bar{e}^{*}$ will you be obedient $8 ; i^{* * *} \bar{a}$ where are you going $9 ; * * * \ddot{o} \bar{o}$ home

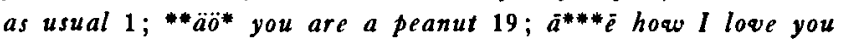
$10 ; * \ddot{a} a^{*}$ who are you $5 ; \bar{a}^{* *} i$ you wouldn't allow it $13 ; \ddot{a}^{*} \ddot{a}^{*}$ are you part of it 13; **öe* do you hear me 2 ; "aä know you not $12 ; \bar{o}^{* *} i *$ you wouldn't have it $11 ;{ }^{*}{ }^{* *} \ddot{a}$ you are a nun 8; $\tilde{o}^{* * *} \dot{0}$ roll up your hose $4 ; \ddot{a}^{* * *} i^{*}$ you have a part in it 8 ;

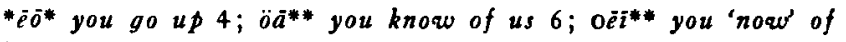
it $10 ; \ddot{o}^{*} \bar{a}$ you were 'hoit" 6 ; " $\bar{e} \bar{e}$ what do you do $4 ;{ }^{* *} \bar{i}^{*} \ddot{b}$ what are you doing $3 ;^{*} \bar{o}^{*} a^{*} I$ wouldn't try it $4 ; i 0^{* * *}$ are you out of it 4 (new day); "öe* I do see that $9 ; \bar{a}^{*} \bar{o}^{*}$ elle n'est partie 11; $\ddot{o}^{* * *} i$ do not say your part $28 ; \bar{e} \bar{e}^{* *}$ take leave of it 7 ; $\ddot{a} i^{*}$ oh, are you $5 ;{ }^{* *} \bar{o} \ddot{e}$ got your visa $14 ; \bar{o}^{* *} \ddot{a}^{*}$ elle ne sait pas $5 ;{ }^{* * *} \bar{i} \bar{e} p$-p-partie $11 ; \ddot{a}^{*} \bar{o}^{* *}$ are you going $7 ;$ *o $^{*}$ who are you $3 ;{ }^{*} \dot{e}^{*} \bar{e}$ vis-a-vis $6 ;{ }^{*} \bar{o}^{* * *} \ldots$ knows of it 13 ; a $\ddot{o}^{* *}$ ...dreams of it $13 ; \bar{e}^{*} \bar{a}$ do it again $4 ; *^{* * *} \bar{o}$ who are you 4 ; $\bar{o}^{* *} \bar{a}^{*}$ how do you amaze her 7 ; $e^{* * *}$ have you tavo cents $11 ; *^{*} \bar{o}^{*}$ maybe $19 ; \ddot{a}^{* *} \ddot{o}$ hard to repeat $3 ; \bar{e}^{*} \bar{e}$ think of you 4 ; öa* none of that 3 ; *iä I don't know $9 ;{ }^{*} \bar{o}^{* *} \bar{o}$ a girl ought to know ; $\bar{e}^{*} \bar{e}^{* *}$ vis-à-vis . . . 8; *iä night owl $3 ; \bar{o}^{*} \bar{e}^{*}$ hate to use them $10 ;{ }^{*} i^{* *}$ do you ask him 7 ; $i i^{*}$ how are they 10 ; ${ }^{*} \bar{o}^{*} \bar{o}^{*}$ carry them over $5 ; \ddot{o}^{*} \bar{e}^{* *}$ do you have use of them 5; (rest); ǟ*** do I know of it 4 ; ***e-e are you, too 23 ; $\bar{e} \bar{o}^{* *}$ you owe of them $10 ;{ }^{* *} \ddot{o}^{*}$ are you doing that $8 ; \ddot{a}^{*} a$ are you old 3 ; *īi see-saw $10 ;{ }^{*} a^{* *} \delta$ ah, 'oo know $18 ; \bar{e}^{* *} \hat{o}^{*}$ you are a peacock 3 ; äe** are you a nut 16; $\ddot{o}^{* * *} \bar{a}$ who else do I know $5 ;{ }^{*} \bar{o} \bar{o}$ are you there $3 ;{ }^{*} \bar{e}^{* *} \bar{a} I$ do not know $5 ; \ddot{a}^{* * *} \ddot{o} I$ 'd rather have you $11 ; i \bar{o}^{* *}$ I know you not $7 ; \ddot{o}^{* * *} \bar{e}$ will you have tea 9; $i a^{*}$ all right $3 ;{ }^{* *} \tilde{o}^{*} \bar{i}$ I'll ring the bell 4; $\ddot{a}^{* *} \bar{e}$ Have I of you 20.

Thematic Classification. Such a list of responses may be analysed without considering its test value and without appeal to other 
clinical or experimental knowledge of the subject. The list shows little coherence in the ordinary rhetorical sense, but it will be seen that certain themes appear and reappear frequently, and these may be arranged in groups. There are many possible methods of classification which are equally well recommended a priori, but from a summary acquaintance with material of this kind certain categories appear to be of special significance or convenience. In order to include as many actual data as possible, I shall give a classification of the responses of another subject $(G)$ noting only the number of responses for $A$ falling into each class.

I. Personal affairs. In the first class responses are selected according to the personal pronouns that they contain.

I, (me, my): I'll do that, I'll do it again, I'll meet him again, I'll do my part, I'll go up, I'll drop in, Maybe I did, Someone made me sick, Going to let me know. (A: 14 responses).

You (your, yours): Where are you, Were you away, Were you on the strect, Were you among the most, Wore you up, How far did he take you. Do you look tired, Arc you a tiger, Are you using the car, Have you a doll, Have you the paper, Have you found them, Have you got a part, Have you what I'll borrow, Have you nineten thousand, You are up, You waiver, Some day you'll see.

(A: Subclasses as follows:-

You alone-31 questions, 17 statements.

You and $I$ (me, etc.) -10 responses.

You and he (him) or she (her) -5 responses.

He (she, him, her, etc.): He made a run, He bought a top, Is a boy, Is he appeasable, Dors he love peanut butter, Did he go with them, Is he gone, Was he cold, Did he ever do that, Did he pop up, Has he found out, (Another fool guy.) (A: Two examples in French).

Other personal pronouns: And so were we, So did we, May we ever, How about them, Whatever they be. (A: None).

II. Injunctions. The second class is composed of injunctions, with sub-classes with $d o, g o$, and so on, as required.

Do: Do that, Do it often, Do not do that, Don't do that, Do your part, Do not go too far, Don't lay down. (A: Seven cases).

Go: $G o$ up, Go down some, Go about, Go roll about, Go through the loop, Go mect the cardinal, Go to movie, Go a- 
golfing, Go to Palm Beach, Go with me, Go home. (A: One case).

Other injunctions: Belicve us too, Roll about, Roll off a boulder, Roll the voque', Hire a bootblack, Throw a bead ring, Pass me the fudge, Give me the whel, Tell her I'll be slow, Make a full stop. (A: Eleven cases).

III. Spccial Themes. These are put together from responses which belonic in other formal classes but which show a pronounced common theme.

The Boat: All in the boat, Row your boat, Pull the boat us, Keep our boat, See the boat, Have you looked at the boat, All aboard the boat, Go on a boat, For up on the boat, Who's on the boat, Was he on the boat, Lrave our ship.

Love: I'll love you, Do you love me, Are you sure you love me, Do they love me, The man I love, Ilas he my low', Does he love you.

Baby: The baby, See the balie, Have a baby, Have a baby, Have a baby.

Religion: Praise our Father, Father above, Father in Heaven, Today our trust, God the Father, Father will pardon us, Jesus Christ, Ye who are, Follower of Jesus, Our lady, Come near the earth, God of Love.

Books: How about a book, Have you the book, Have you that book, Have a blue book, Can you read the book, I've a book, There are my books.

Clothes: Do you need a new coat, Have you an evening coat, Do you have your coat, Do you have a stocking, An overcoat, Bring your clothing, Drop your clothes.

Weather: Too hot, Too hot, Foul zurather, North cast wind, Have you cold weather. (A: No thematic classes exist for A except possibly a class based upon know. The examples have been distributed here in other ways).

IV. The External World. As we have seen, very little is said about external simuli, but a certain number of nouns, adjectives, and so on, are given in absolute position. These might be regarded as a sort of mise-en-scène for the thematic classes.

Objects: A knife and spoon, $A$ deep pond, $A n$ automobile, An automobile, $A n$ old woman, Maid, Homer and McGee, The thirteenth egg, Saturday Evening Post, $A$ cartload of gnats, Cold water, $A$ bowl of 'ola,' $A$ polo pony, Slow motion, Lazybones, House of Parliament, Houses of Parliament, A great heart, Old spy, No mover, rock vouvel, roller skates. (A: Twenty-two items). 
Attributes: Good and tired, Two a day, Five fect, Five dollars each, Walking alone, Though enduring it, Almost, Ah bcautiful, How beautiful, Above me, Far above me, Far about, Far away, Far from home, Far gone, Far gone, Far gone, Far gone, All gone. (A: Four items).

V. Miscellaneous. The foregoing classes exhaust the protocols of the two subjects except for the following:

(a) Nonsense, laughs, sighs, etc.: Ha-ha, Ah-ah, ho-hum, $h m-h m, E O X, O V E, A b u l-a b u$. (A: No cases).

(b) Greetings and exclamations: Good-night, Good-bye, Ladies and gentlemen, I beg your pardon, How are you. (A: Five cases).

(c) Responses related to extraneous stimuli: No cases. Four cases).

(d) Unclassified and incomplete: Leave out, Have more margin, Have a bad heart, Seven eight, Is it all done. (A: Five cases).

Such a method of classification is not meant to be final, for it will require modification or even replacement as further material is collected and clinical significances are worked out. The example indicates what may be done by way of rough analysis at the present time. The principal result is that in spite of the absence of external differentiating stimuli the responses fall into thematic or formal groups, many of which are homogeneous and coherent.

\section{The Verbal Summator as a 'Test'}

It is not my intention to comment upon the diagnostic value of this material, for it would require going beyond a description of the method to a clinical study of each subject. A comparison of the results from the verbal summator with those from thematic apperception, ink-blot, and other tests and from clinical investigations is now being made as part of a cooperative study at the Harvard Psychological Clinic, a report of which will appear later. So far as a 'test' is concerned, the present study may be regarded as a sort of calibration, and, it remains simply to note the technical restrictions upon the free use of summated responses and of collateral data in the interpretation of individual behavior.

Since a fairly close resemblance in word-frequency and worddistribution has been demonstrated between a block of summater re- 
sponses and a sample of standard speech, it might be argued that no special significance of the summated material should be inferred. That is, it might be said that the summator simply evokes the commonest verbal responses in the repertoire of the subject. But the study of word-frequency has little to do with the 'content' or the subject matter of speech. The graphs in Figures 3 and 4 are available and intelligible without reference to the meanings of the words they represent. As defined in such a count, a word may be regarded merely as a geometrical or acoustical form. The use of the summator as a test rests upon a distinction between the subject matters of normal and summated speech and between the factors responsible for each. In normal speech the responses 'refer to' external stimuli-to whatever is being 'talked about.' In the case of summated behavior these stimuli are eliminated so far as possible. The resulting difference is that where the particular form occurring in normal speech can generally be accounted for by pointing to a particular stimulus, in summated speech the occurrence must be attributed to the special strength of the response itself. The advantage of the summator as contrasted with a direct study of normal speech is that, although the effect of particular stimuli may be eliminated in the latter case by the use of large samples, it becomes at the same time impossible to deal with the single instance, which from the point of view of individual behavior is the important thing.

The content of the responses may be used in interpreting individual behavior when allowance has been made for $(a)$ the kind of instructions given, $(b)$ the presence of extraneous stimuli, and ( $c$ ) perseveration of form. Perseveration of theme does not effect the significance. The content may be supplemented with the following possibly significant data: (a) the number of repetitions required relative to the average for the individual and $(b)$ the distortion of the sample-either phonemic, if that is practical, or of the number of syllables. Both of these data indicate the relative strength of a response, although other factors doubtless enter in. One potentially significant datum, which $I$ have not yet been able to deal with, is the occasional nonsensical response, as, for example, oil à la main, or bombeeza. These might be expected to be disguised responses, which would resolve themselves into conventional forms with some slight change of accent or pronunciation. 


\section{Conclusion}

The phenomena revealed by the verbal summator are common enough in human behavior, but as ordinarily observed they do not easily submit to a rigorous formulation or to measurement. Chaining, for example, is responsible for such coherence in normal speech as is not a reflection of coherence in the external stimulation. The summator is not especially valuable in the study of chaining, because the patterns of successive samples impose restrictions upon 'free association.' On the other hand the same restrictions make the examples of perseveration of form more illuminating than in normal speech because of the relative absence of perseveration of theme. Perseveration of form constitutes much of the special character of poctry and of such prose as that of James Joyce, but in expository writing its characteristic effects are taboo. We are enjoined not to repeat a word too frequently, not to alliterate, not to rhyme, and so on. There is good reason for this, for the perseveration of form is an accidental and adventitious influence which confuses the relation between speech and its referents. There is likewise nothing new about the thematic side of verbal summation. In the design and production of unclear patterns of speech-sounds we are only reproducing a very common condition. The behavior of a subject in 'reading into the sounds some meaning of his own' is part of the experience of most people. The paranoid who overhears criticisms of himself and the mystic who hears voices from the other world are only extreme cases of these familiar phenomena. The advantage of the summator is that it brings the subject into the laboratory, and through better control of the stimulating material improves upon casual observation as a means of discovering the basic laws governing these aspects of behavior.

\section{Appendix: A Simple Repeating Device}

The commercial devices that I have seen for repeating parts of phonograph records are unnecessarily complex and have other ohjectionable features. The time required for the change-back is usually so long that rapid repetition is impossible. Likewise the needle may be lowered without respect to the rotational position of the record, with the result that successive playings begin at various positions within a length of needle-path equal to one revolution of the record and the timing is disturbed. A strictly rhythmi- 
cal repetition is highly desirable in order to allow the subject to set himself for each presentation. The device described below avoids these objections. It is easily constructed and may be installed in a standard phonograph without serious alteration. The construction described is adapted to an R. C. A.-Victor Portable Electrola.

A general notion of the action of the device may be obtained from the: plan in Figure 6 and the sketch in Figure 7. The pick-up arm $(A)$ is lifted by means of a brass $\operatorname{rod}(B)$ fastened to it and extending horizontally

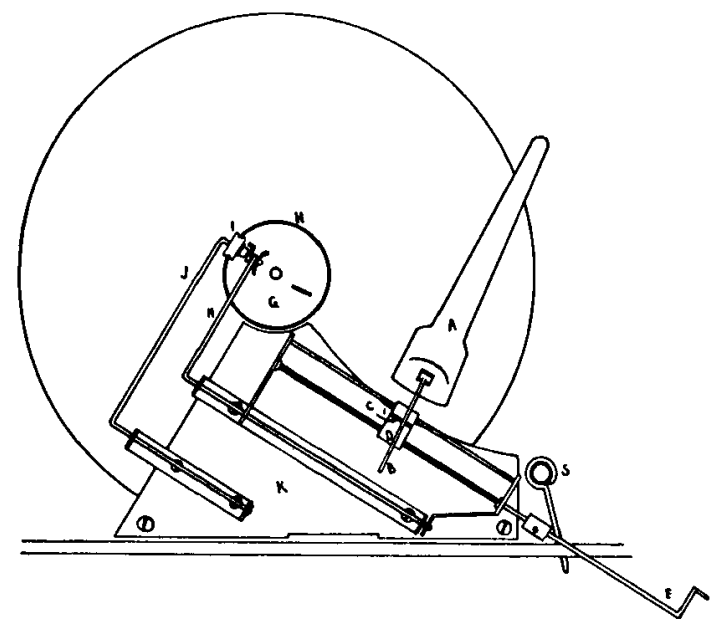

FIGURE 6

Top View of Repeating Device

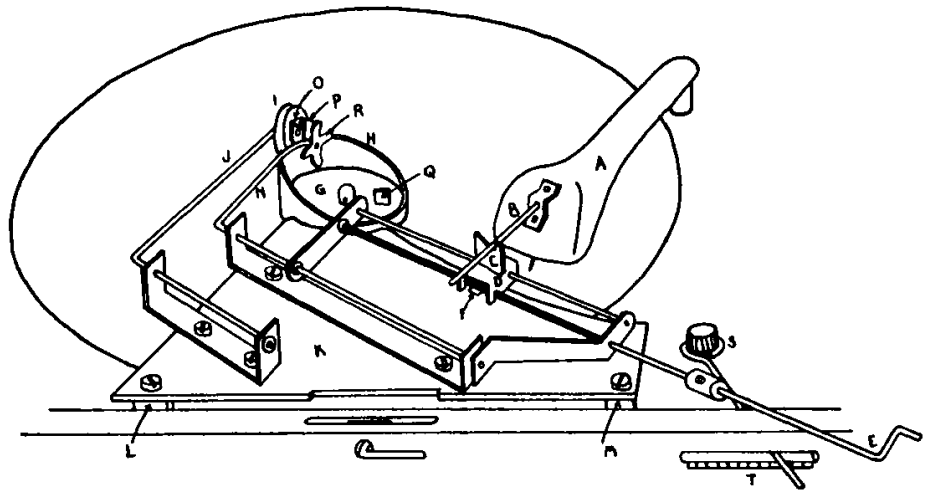

FIGURE 7

Sketch of the Repeating Device Attached to a Portabie Phonograph 
forward about two inches. The three necessary movements of the pickup are accomplished by a single vertical movement of the notched tab $(C)$ When the needle is on the record the tab is free of the rod and the latter moves centripetally as the record is played. When the tab is raised, the rod strikes the sloping edge and slides centrifugally until it strikes the vertical edge of the notch. The slope of the notch need not be great to effect this and must not be too great if the needle is not to drag along the record. As the tab is lowered, the needle is set on the record at a point determined by the position of the tab. This is varied by moving the carriage $(D)$ upon which the tab is mounted. The carriage slides upon two transverse rods, one of which is a screw, and its position is varied by turning the screw. A prolongation of the screw $(E)$ extends through a slot in the cover of the phonograph and makes it possible to adjust the position while the cover is closed. To permit quick adjustment, the screw is held against the carriage by a spring clip $(F)$; by lifting the screw end of the carriage slightly the carriage may be moved to any position required.

The vertical movement of the carriage is effected by the motor of the phonograph. A $2 \frac{1}{2}$-inch disc of brass $(G)$ is pressed into an eccentric collar $(H)$ and fitted over the shaft of the motor, to which it may be held with a cotter-key. With each revolution of the disc the eccentric collar lifts and lowers a wheel $(I)$ at the end of an arm $(J)$, which is mounted on a plate of brass $(K)$ extending over the record and fastened to the floor of the phonograph on two brass blocks $(L)$ and $(M)$. The screw at $(L)$ may be removed and the whole device swung out away from the record when the latter is changed, the collar being removed separately. The single arm at $J$ will not suffice, because the pick-up is not to be lifted with every revolution. A second $\operatorname{arm}(N)$ is therefore attached to the plate, and this arm controls the transverse rods and carriage. The second arm is lifted only once in $n$ revolutions, where $n$ (which may conveniently be from 3 to 8 ) is determined as follows. The first arm $(J)$ carries a shelflike bracket $(O)$ projecting toward the second arm $(N)$ and the latter carries a similar bracket $(P)$ overlapping this. But the bracket on $N$ may not always be in an upright position, for it turns on a shaft inserted through the end of the arm. The shaft carries on the other side of the arm a wheel $(R)$ with a number of projections equal to the number of revolutions between repetitions required. At each revolution (when both arms are in their lowest position) the lowest projection from $R$ is struck by an upright block $(Q)$ fastened to the disc $G$, and $R$ is turned. Figure 7 represents the device at a moment when the brackets have engaged and arm $N$ has been lifted to its highest position by arm $J$. The needle is off the record and the extension $B$ has moved against the end-stop of tab $C$. As the record revolves one half turn both arms will fall, the needle will be set upon the record, and the upright $Q$ will strike the lowest projection on $R$ and 
disengage the brackets. They will engage again four revolutions later. In Figure 5 the bracket on $N$ is shown in a position immediately preceding engagement.

In beginning the experiment the carriage is set nearest the conter of the record and is finely adjusted with the screw until the needle strikes the groove desired for the last sample on the record. In changing to a new sample the screw is turned clockwise and the carriage moved outward. The samples are used backward, in order to avoid pressing the end of the tab against the arm in making a change while the needle is on the record.

On the phonograph here used it was found convenient to press a brass rod $(S)$ onto the volume control and to allow it to extend through a slot in the case of the machine. It was then possible to change the samples and control the volume without opening the phonograph. If it is desired to play selected samples rather than to take them in order, a calibration card may be attached to the brass plate $(K)$ and a pointer to the arm $B$. As the record is played the sample may be noted on the card at the position indicated by the pointer and easily found again when needed.

This device, ready for attachment to a phonograph, can be supplied by Mr. R. Gerbrands of the Harvard Psychological Laboratory for about $\$ 15.00$.

\section{REFERENCES}

1. Paget, R. Human speech. London: Kegan Paul, 1930. Pp. 360.

2. ZIPP, G. K. The psycho-biology of language. Boston: Houghton, Miftin, 1935. Pp. ix +336 .

3. Skinner, B. F. A failure to obtain disinhibition. J. Gen. Psychol, 1936, 14, 127-135.

4. Fletcher, H. Speech and hearing. New York: Van Nostrand, 1929. Pp. $x v+331$.

Harvard University

Cambridge, Massachusetts 